\title{
Antithrombotic therapy in patients with atrial fibrillation undergoing percutaneous coronary intervention
}

\author{
Anetta Undas ${ }^{1,2}$, Leszek Drabik ${ }^{2,3}$ \\ ${ }^{1}$ Institute of Cardiology, Jagiellonian University Medical College, Krakow, Poland \\ 2John Paul II Hospital, Krakow, Poland \\ ${ }^{3}$ Department of Pharmacology, Jagiellonian University Medical College, Krakow, Poland \\ Correspondence to: \\ Prof. Anetta Undas, MD, PhD, Institute of Cardiology, Jagiellonian University Medical College \\ 80 Prądnicka Street, 31-202 Kraków, Poland, E-mail: mmundas@cyf-kr.edu.pl
}

The management of atrial fibrillation (AF) in patients who have undergone percutaneous coronary intervention (PCl) with stent implantation is challenging. Oral anticoagulation has been shown to significantly reduce the risk of stroke in AF, whereas dual antiplatelet therapy prevents major adverse cardiovascular events, including stent thrombosis after $\mathrm{PCl}$. A typical triple antithrombotic therapy, involving an anticoagulant, i.e. vitamin $\mathrm{K}$ antagonist (VKA), together with aspirin and $\mathrm{P} 2 \mathrm{Y}_{12}$ inhibitor, usually clopidogrel, has been shown to minimize ischemic and stroke risks, but is associated with increased risk of major bleeding. The use of dabigatran, rivaroxaban, or apixaban in combination with antiplatelet agents lowers the risk of major bleeding and makes it an option preferred over triple therapy in the majority of $\mathrm{PCl}$ patients with AF. The consistency across randomized controlled trials on combination therapy with non-vitamin $\mathrm{K}$ antagonist oral anticoagulant (NOAC) and clopidogrel, including patients with acute coronary syndromes, led to changes in everyday practice. However, the use of triple and dual antithrombotic therapy at high bleeding risk should be individualized. The present review summarizes available data on the efficacy and safety of antithrombotic therapy in AF patients undergoing $\mathrm{PCl}$ in the era of NOAC.

Keywords: atrial fibrillation, percutaneous coronary intervention, double therapy, triple therapy, non-vitamin $\mathrm{K}$ antagonist oral anticoagulant

The estimates show that up to $15 \%$ of atrial fibrillation (AF) patients will require percutaneous coronary intervention with stent implantation (PCl) during their lifetime (1). The most frequent indication for double or triple antithrombotic therapy (DAT, TAT), including a P2Y ${ }_{12}$ inhibitor with or without aspirin and an oral anticoagulant (OAC), is an acute coronary syndrome (ACS) with concomitant AF, mechanical heart valves, left ventricular thrombus, or recent venous thromboembolism (2). Decision making on the length and intensity of antithrombotic therapy in patients with AF and $\mathrm{PCl}$ is based on the predicted risk of thromboembolism and bleeding. Traditionally TAT involving vitamin $K$ antagonist (VKA), mostly warfarin, aspirin and clopidogrel was administered for $6-12$ months to reduce the risk of stroke (with VKA) and coronary thrombotic events (with antiplatelet drugs) (3). Available data clearly showed that TAT is associated with a very high risk of bleeding compared with DAT therapy reduced to an oral anticoagulant and a single antiplatelet agent. The 30-day bleeding rates in patients with TAT, including VKA, reaches $2.2 \%$, growing to $12 \%$ in one-year follow-up (4), worsening prognosis. Major bleeding in patients with ACS is associated with a fivefold higher risk of death within 30 days (5). High-quality randomized controlled trials (RCTs) providing direct comparisons between diverse DAT and TAT regimens suggest the superiority of DAT after an initial short-period treatment with TAT for the majority of patients with AF undergoing $\mathrm{PCl}(6-9)$. 


\section{Oral anticoagulants in atrial fibrillation}

OAC in AF patients reduces the risk of stroke and systemic thromboembolism (SE) by more than $60 \%$ demonstrating superiority over aspirin monotherapy or clopidogrel-based dual antiplatelet therapy (DAPT) (10). Non-vitamin $\mathrm{K}$ antagonist oral anticoagulants (NOAC) including apixaban, edoxaban, dabigatran and rivaroxaban, are recommended in preference to VKAs in patients with nonvalvular AF. In a meta-analysis of seminal phase 3 AF RCTs, NOACs reduced all-cause mortality, the risk of stroke or SE and intracranial bleeding by $10,19 \%$ and $52 \%$ respectively, but increased gastrointestinal $(\mathrm{Gl})$ bleeding risk by one quarter compared with warfarin (11). An increase in Gl bleeds on NOACs was driven mainly by results of seminal RCTs evaluating dabigatran and rivaroxaban. Nevertheless, reduction in bleeding-related mortality (relative risk, RR: 0.54, 95\%; Cl: 0.44-0.67) for all NOACs as compared with warfarin has been demonstrated (12).

\section{Dual antiplatelet therapy after $\mathrm{PCl}$}

There is consensus on a 6-month DAPT after $\mathrm{PCl}$ for stable angina. A shorter (1-3 months) duration of DAPT should be considered in patients at high bleeding and low ST risk. In patients after ACS, European Society of Cardiology (ESC) guidelines recommend default 12-month DAPT and shorter its duration may be considered among those at high bleeding risk $(13,14$. High-risk features for ST that may be precipitated by too early discontinuation of DAPT, include stenting of the left main artery, or proximal left anterior descending artery or last remaining patent artery, suboptimal stent deployment, large stent length $(>60 \mathrm{~mm}), \mathrm{PCl}$ of the bifurcation with two stents implanted, treatment of chronic total occlusion and previous ST, diabetes mellitus and chronic kidney disease $(2,15)$. Prolonging DAPT duration may substantially reduce the risk of ischemic events in high-risk populations. It has been found that the therapy with clopidogrel, ticagrelor or prasugrel extended beyond 12 months is associated with reduced ischemic events and ST but increased bleeding complications with no change in the mortality rate. The greatest benefit of long-term DAPT with ticagrelor $60 \mathrm{mg}$ b.i.d. has been observed in high-risk post-myocardial infarction (MI) patients with diabetes, multivessel coronary artery disease, and peripheral artery disease (16).

\section{Randomized trials on combination anticoagulant and antiplatelet therapy}

Several RCTs have compared TAT with DAT in AF patients undergoing coronary stenting. Early moderate-size studies focused on the efficacy and safety of shor- tening VKA-based TAT, with the largest impact of the WOEST and ISAR-TRIPLE trials.

The WOEST trial (What is the Optimal antiplatElet and anticoagulant therapy in patients with oral anticoagulation and coronary StenTing) compared TAT (VKA + clopidogrel + ASA) with DAT (VKA + clopidogrel) in patients undergoing $\mathrm{PCl}$ who required $\mathrm{OAC}$ due to $A F$, mechanical heart valve and other reasons, e.g. apical aneurysm, pulmonary embolism, peripheral artery disease. Bleeding episodes were almost 3-fold lower in the DAT group (hazard ratio, HR: $0.36,95 \% \mathrm{Cl}: 0.26-$ $0.50)$. In the WOEST trial, only $69 \%$ of patients in the TAT group had AF, and $69 \%$ of participants in this study used a 12-month TAT compared with other studies (4). The ISAR-TRIPLE trial (Triple Therapy in Patients on Oral Anticoagulation After Drug Eluting Stent Implantation) evaluated shorten the duration of clopidogrel therapy from 6 months to 6 weeks in 614 patients receiving VKA who underwent PCI (one-third with ACS). The primary composite end-point of death, MI, ST, ischemic stroke or Thrombolysis in Myocardial Infarction (TIMI) major bleeding at 9 months, did not differ between the 6-week and 6-month (HR: 1.14, 95\% Cl: 0.68-1.91) (17). Although WOEST and ISAR-TRIPLE studies were underpowered, shortening of TAT emerged as a safe option in patients with AF and ACS and/or an elective PCI. Based on results of the WOEST and ISAR-TRIPLE studies, the 2015 ESC guidelines for the management of ACS in patients presenting without persistent ST-segment elevation recommended shortening TAT duration in patients at high bleeding risk to one month, irrespective of the stent type (13).

The introduction of the NOACs has added to the complexity of treatment decisions in AF patients, but showed new opportunities increasing the safety of anticoagulant patients. Until now, 4 large RCTs compared the risk-to-benefit ratio of warfarin and the NOACs in combination with antiplatelets (Table 1).

The PIONEER AF-PCI trial (an open-label, randomized, controlled, multicenter study exploring two treatment strategies of rivaroxaban and a dose-adjusted oral vitamin $\mathrm{K}$ antagonist treatment strategy in subjects with atrial fibrillation who undergo percutaneous coronary intervention) tested two lower rivaroxaban doses (15 mg o.d. plus ${\mathrm{P} 2 \mathrm{Y}_{12}}_{12}$ inhibitor for 12 months and 2.5 mg b.i.d. plus DAPT for 1,6 , or 12 months) versus VKA plus DAPT for 1,6 , or 12 months. The TIMI major bleeding was lower in the two groups receiving rivaroxaban (HR: $0.59,95 \% \mathrm{Cl}: 0.47-0.76$; HR $0.63,95 \% \mathrm{Cl}$ : $0.50-0.80$; respectively) compared with the TAT group. There was no difference in all-cause death, death from cardiovascular causes, MI, or stroke between the three groups (7).

The REDUAL-PCl trial (A Prospective Randomised, Open Label, Blinded Endpoint Study to Evaluate DUAL Antithrombotic Therapy With Dabigatran Etexilate $(110 \mathrm{mg}$ and $150 \mathrm{mg}$ b.i.d.) Plus Clopidogrel or Ticagrelor vs. 
TABLE 1. Main characteristics of seminal NOAC trials in patients with atrial fibrillation following PC

\begin{tabular}{|c|c|c|c|c|}
\hline & $\begin{array}{l}\text { PIONEER AF-PCI } \\
(n=2124)\end{array}$ & $\begin{array}{l}\text { RE-DUAL PCI } \\
(n=2725)\end{array}$ & AUGUSTUS $(n=4614)$ & $\begin{array}{l}\text { ENTRUST-AF PCI } \\
(n=1506)\end{array}$ \\
\hline Study year & 2016 & 2017 & 2019 & 2019 \\
\hline $\begin{array}{l}\text { Time science index } \\
\text { event }\end{array}$ & 72 hours & 120 hours & 14 days & 5 days \\
\hline Treatment strategies & $\begin{array}{c}\text { - Rivaroxaban } 15 \mathrm{mg} / \mathrm{d}+ \\
\text { a } \mathrm{P}^{2} \mathrm{Y}_{12} \text { inhibitor } \\
\cdot \text { Rivaroxaban } 2.5 \mathrm{mg} \\
\text { b.i.d + DAPT }- \text { VKA + } \\
\text { DAPT }\end{array}$ & $\begin{array}{c}\cdot \text { Dabigatran } 110 \mathrm{mg} \\
\text { b.i.d + a P2Y } 12 \text { inhibitor } \\
\cdot \text { Dabigatran } 150 \mathrm{mg} \\
\text { b.i.d + a P2Y } Y_{12} \text { inhibitor } \\
\cdot \text { VKA + DAPT }\end{array}$ & $\begin{array}{c}\text { - Apixaban } 5 \text { mg bid+ DAPT } \\
\text { - Apixaban } 5 \text { mg b.i.d + a } \\
\text { P2Y } 12 \text { inhibitor } \\
\text { • VKA + DAPT } \\
\text { - VKA + a P2Y } 2 Y_{12} \text { inhibitor }\end{array}$ & $\begin{array}{c}\text { - Edoxaban } 60 \mathrm{mg} / \mathrm{d} \\
+ \text { a P2Y }_{12} \text { inhibitor } \\
\text { VKA + DAPT }\end{array}$ \\
\hline \multicolumn{5}{|l|}{ Clinical setting } \\
\hline Elective PCl & $61.5 \%$ & $49.5 \%$ & $38.8 \%$ & $48.0 \%$ \\
\hline Primary $\mathrm{PCl}$ & $38.5 \%$ & $50.5 \%$ & $37.3 \%$ & $52.0 \%$ \\
\hline $\begin{array}{l}\text { Medically managed } \\
\text { ACS }\end{array}$ & $0.0 \%$ & $0.0 \%$ & $23.9 \%$ & $0.0 \%$ \\
\hline \multicolumn{5}{|l|}{$\mathrm{P} \mathrm{Y}_{12}$ inhibitor } \\
\hline Clopidogrel & $94.4 \%$ & $87.9 \%$ & $92.6 \%$ & $92.0 \%$ \\
\hline Ticagrelor & $4.3 \%$ & $12.1 \%$ & $6.2 \%$ & $7.0 \%$ \\
\hline Prasugrel & $1.3 \%$ & $0.0 \%$ & $1.2 \%$ & $0.5 \%$ \\
\hline $\begin{array}{l}\text { TAT regimen duration } \\
\text { (months) }\end{array}$ & 1.6 or 12 & 1 (BMS) or 3 (DES) & 6 & $1-12$ \\
\hline Follow up (months) & 12 & 14 & 6 & 12 \\
\hline Safety end-point & $\begin{array}{c}\text { A composite of TIMI } \\
\text { major bleeding or minor } \\
\text { bleeding }\end{array}$ & $\begin{array}{c}\text { Major or CRNM ISTH } \\
\text { bleeding }\end{array}$ & $\begin{array}{l}\text { Major or CRNM ISTH } \\
\text { bleeding }\end{array}$ & $\begin{array}{c}\text { Major or CRNM ISTH } \\
\text { bleeding }\end{array}$ \\
\hline MACE definition & $\begin{array}{l}\text { A composite of CV } \\
\text { death, MI or stroke, and } \\
\text { ST }\end{array}$ & $\begin{array}{l}\text { A composite of all-cause } \\
\text { death or ischemic event } \\
\text { (including stroke, MI, } \\
\text { ST, SE, or unplanned } \\
\text { revascularization) }\end{array}$ & $\begin{array}{l}\text { A composite of all-cause } \\
\text { death or ischemic event } \\
\text { (including stroke, MI, ST } \\
\text { definite/probable, urgent } \\
\text { revascularization) }\end{array}$ & $\begin{array}{l}\text { A composite of CV } \\
\text { death or ischemic } \\
\text { event (including stro- } \\
\text { ke, MI, ST definite, } \\
\text { SE) }\end{array}$ \\
\hline
\end{tabular}

AF, atrial fibrillation; $\mathrm{PCl}$, percutaneous coronary intervention; VKA, vitamin $\mathrm{K}$ antagonist: DAPT, dual antiplatelet therapy; ACS, acute coronary syndrome; TAT, triple antithrombotic therapy; BMS, bare-metal stent; DES, drug-eluting stent; OAC, oral anticoagulation; TIMI, Thrombolysis in Myocardial Infarction; CRNM, clinically relevant non-major; ISTH, International Society on Thrombosis and Haemostasis; MACE, major adverse cardiac events; MI, myocardial infarction; CV, cardiovascular; SE, systemic embolism; ST, stent thrombosis.

Triple Therapy Strategy With Warfarin (INR $2.0-3.0$ ) Plus Clopidogrel or Ticagrelor and Aspirin in Patients With Non Valvular Atrial Fibrillation That Have Undergone a Percutaneous Coronary Intervention With Stenting) which assessed DAT (dabigatran $110 \mathrm{mg}$ bid or $150 \mathrm{mg}$ bid and a P2Y 12 inhibitor, mostly clopidogrel) with TAT (warfarin and clopidogrel and ASA), showed a reduction of major and non-major bleeding events in the DAT group with $110 \mathrm{mg}$ dabigatran (HR: 0.52, 95\% $\mathrm{Cl}: 0.42-0.63)$ and the DAT group with $150 \mathrm{mg}$ dabigatran (HR: 0.72, 95\% Cl: 0.58-0.88) compared with TAT. There was no difference in ischemic complications and death between DAT and TAT strategy (8).

The AUGUSTUS trial (An Open-label, $2 \times 2$ Factorial, Randomized Controlled, Clinical Trial to Evaluate the Safety of Apixaban vs. Vitamin K Antagonist and Aspirin vs. Aspirin Placebo in Patients With Atrial Fibrillation and Acute Coronary Syndrome or Percutaneous Coronary Intervention),the largest trial to date on combined antithrombotic therapy in $\mathrm{AF}$ patients undergoing $\mathrm{PCl}$, showed that apixaban $5 \mathrm{mg}$ b.i.d. reduces the risk of major bleeding or clinically relevant non-major (CRNM) bleeding compared with VKA (HR: 0.69, 95\% Cl: 0.580.81). Of note, aspirin compared with placebo was associated with higher bleeding risk (HR: 1.89, 95\% Cl: 1.59-2.24). The safest combination therapy apixaban with $\mathrm{P}_{2} \mathrm{Y}_{12}$ involving inhibitor (predominantly clopidogrel) with 16.8 bleeding events /100 patients-years observed vs 49.1 events /100 patients-years in the group with $\mathrm{VKA}+$ aspirin $+\mathrm{P}_{2} \mathrm{Y}_{12}$ inhibitor (9).

The ENTRUST-AF PCI trial (Evaluation of the safety and efficacy of an edoxaban-based compared to a vitamin $\mathrm{K}$ antagonist-based antithrombotic regimen in subjects with atrial fibrillation following successful percutaneous coronary intervention ( $\mathrm{PCl}$ ) with stent placement, $n=1506$ ) demonstrated edoxaban $60 \mathrm{mg}$ o.d. + $\mathrm{P} \mathrm{Y}_{12}$ inhibitor for 12 months to be non-inferior to VKA $+\mathrm{P}_{2 Y_{12}}$ inhibitor + aspirin (100 mg once daily, for 1-12 months) regarding major or CRNM bleeding events (HR 0.83, 95\% Cl 0.65-1.05) (6). 


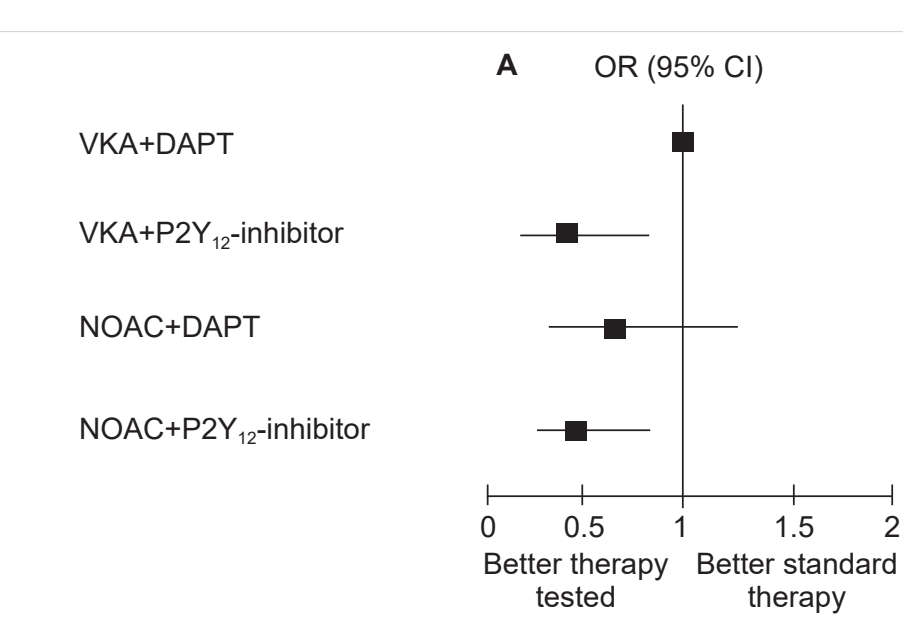

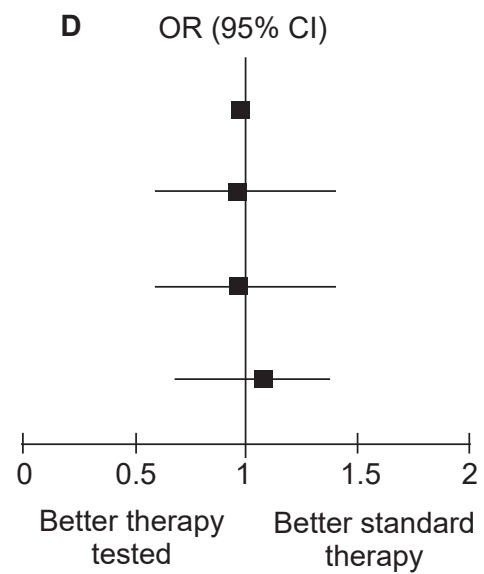

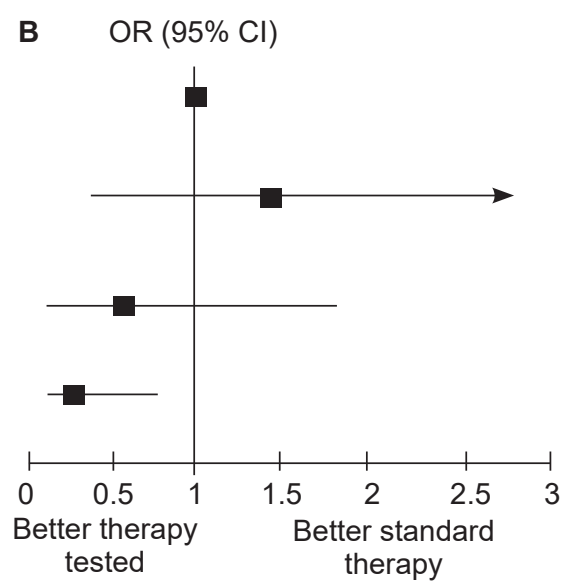

E $\quad$ OR $(95 \% \mathrm{Cl})$
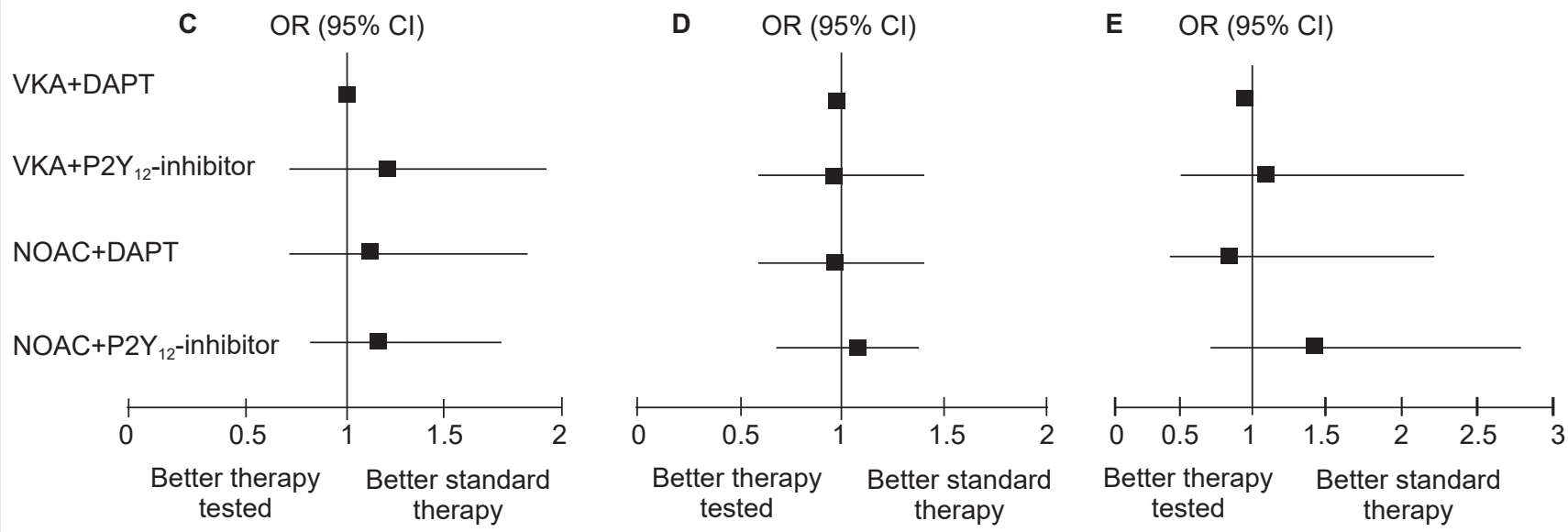

FIGURE 1. Safety and efficacy of different anticoagulant regimens in patients with atrial fibrillation and coronary artery disease. Major bleeding TIMI (Thrombolysis in Myocardial Infarction) - PANEL A, intracranial bleeding - PANEL B, myocardial infarction - PANEL C, major adverse cardiovascular events - PANEL D, stent thrombosis - PANEL E. VKA, Vitamin K antagonist; DAPT, dual antiplatelet therapy; $\mathrm{P}_{2} \mathrm{Y}_{12}$ inhibitor plus aspirin; OR, the odds ratios. Based on Lopes et al. (20)

There is strong evidence from several meta-analyses that in patients with $\mathrm{AF}$ undergoing $\mathrm{PCl}$, antithrombotic regimens involving a VKA with DAPT should be generally avoided, whereas the use of a NOAC with a $\mathrm{P} \mathrm{Y}_{12}$ inhibitor without aspirin remains the best option $19)$.

In the most recent systematic review of five RCTs for patients with $\mathrm{AF}$ undergoing $\mathrm{PCI}$ (WOEST, PIONEER AF-PCI, RE-DUAL PCl, AUGUSTUS, ENTRUST-AF $\mathrm{PCl}, \mathrm{n}=11,542$ ) a lower bleeding risk, without a reduction in antithrombotic effectiveness was observed for regimens in which aspirin was discontinued (20). TIMI major bleeding was lower for NOAC plus $\mathrm{P}_{2} \mathrm{Y}_{12}$ inhibitor (RR: $0.52,95 \% \mathrm{Cl}: 0.35-0.79$ ) and VKA plus $\mathrm{P}_{2} \mathrm{Y}_{12}$ inhibitor (RR: $0.57,95 \% \mathrm{Cl}$ : $0.31-$ 1.00), with no difference for NOAC plus DAPT (RR: $0.69,95 \% \mathrm{Cl}: 0.40-1.16)$ as compared with VKA plus DAPT. Major adverse cardiovascular events, including $\mathrm{MI}$ and ST, did not differ between DAT, NOAC plus DAPT and VKA plus DAPT regimen as a reference (Figure 1).

\section{Controversial issues regarding TAT}

Findings across studies on DAT and TAT in patients with $\mathrm{AF}$ and $\mathrm{PCl}$ may be affected by different regimens of NOACs, and P2 $\mathrm{Y}_{12}$ inhibitors, different doses of NOACs and open-label trial design. Seminal trials were largely underpowered for differences in rare events as the incidence of MI, ST, and ischemic stroke. Moreover, major adverse cardiac events (MACE) definition varied among studies. A composite end-point included MI, ST, and stroke in all 4 studies, all-cause death (RE-DUAL $\mathrm{PCI}, \mathrm{AUGUSTUS}$ ), cardiovascular death (PIONEER-AF $\mathrm{PCl}$ and ENTRUST-AF PCl) urgent/unplanned revascularization in the RE-DUAL PCI and AUGUSTUS trials. However, as for the ischemic events, there was a clear trend towards a higher number of $\mathrm{MI}$ and ST with DAT vs. TAT in all 4 trials, and some meta-analyses showed statistically significantly higher rates of MI and/or ST with DAT vs. TAT $(21,22)$. This observation was mainly driven by studies with reduced dose NOACs, especially with dabigatran $110 \mathrm{mg}$ b.i.d. Some me- 
Table 2. Recommendations of the European Society of Cardiology for combined antiplatelet and antithrombotic therapy in AF patients undergoing $\mathrm{PCl}(2)$

Recommendations

TAT limited to $\leq 1$ week after uncomplicated $\mathrm{PCI}$, followed by dual therapy with OAC and clopidogrel should be considered if the risk of stent thrombosis is low or if concerns about bleeding risk prevail over concerns about the risk of stent thrombosis, irrespective of the type of stent used.

TAT with aspirin, clopidogrel, and an OAC for longer than $\geq 1$ month should be considered when the risk of stent thrombosis outweighs the bleeding risk. TAT total duration ( $<6$ months) depends on the assessment of thrombotic/bleeding risk.

DAT with an OAC and either ticagrelor or prasugrel as an alternative to TAT (OAC + aspirin + clopidogrel) may be considered in patients with a moderate-to-high risk of stent thrombosis, irrespective of the type of stent used.

The use of prasugrel/ticagrelor as part of TAT with aspirin and an OAC is contraindicated.

A full dose NOAC (apixaban $5 \mathrm{mg}$ b.i.d., dabigatran $150 \mathrm{mg}$ b.i.d., edoxaban $60 \mathrm{mg}$ o.d., or rivaroxaban $20 \mathrm{mg}$ o.d.) is recommended as preferred over VKA in combination therapy with antiplatelet drugs.

When concerns about high bleeding risk prevail over concerns about stent thrombosis or ischemic stroke, reduced NOAC dose (rivaroxaban $15 \mathrm{mg} \mathrm{o.d}$, dabigatran $110 \mathrm{mg}$ b.i.d) should be considered for DAT and TAT.

In patients treated with VKA in combination therapy with antiplatelets, a target international normalized ratio should be in the range of $2.0-2.5$ and time in the therapeutic range should exceed $70 \%$.

The use of a proton pump inhibitor is recommended in patients at high risk of gastrointestinal bleeding receiving aspirin monotherapy, DAPT, or OAC monotherapy.

Class $^{*} \quad$ Level $^{* *}$

Ila B

IIa

C

${ }^{*}$ Class of recommendation, ${ }^{* *}$ Level of evidence

For abbreviations see Table 1; DAT double antithrombotic therapy, NOAC, non-vitamin $\mathrm{K}$ antagonist oral anticoagulant ta-analysis suggested that the likelihood of an excess of thromboembolic events during DAT vs. TAT was low (23). Lower bleeding risk with DAT compared with TAT was seen regardless of the used bleeding scale, i.e., TIMI bleeding scale in the PIONIER - AF trial versus International Society on Thrombosis and Haemostasis (ISTH) bleeding classifications in other studies.

Optimal TAT duration before DAT and timing of aspirin cessation post an ACS or elective $\mathrm{PCl}$ remain unknown. Seminal trials on a combination of antithrombotic agents in patients with $\mathrm{AF}$ undergoing $\mathrm{PCI}$ have included a large proportion of patients with ACS (38.8$61.5 \%$ ) who have higher ST risk compared with those undergoing elective $\mathrm{PCl}$. A peri-procedural period of TAT was ranging from 3 days (PIONIER-AF) to 14 days after $\mathrm{PCI}$ (AUGUSTUS). Half of the patients in TAT groups of the PIONEER AF-PCI trial continued DAPT for 12 months without a difference in major bleeding or transfusion rates between the NOAC + DAPT and VKA + DAPT groups (15).

The optimal $\mathrm{P}_{2} \mathrm{Y}_{12}$ inhibitor in $\mathrm{ACS}$ or elective $\mathrm{PCl}$ in combined therapy remains to be established. Most studies on DAT and TAT were conducted with clopidogrel, supporting its use in combination therapy. In contrast, there is currently limited evidence to support the use of OACs with ticagrelor or prasugrel in DAT after $\mathrm{PCl}$ as an alternative to TAT. The routine use of ticagrelor or prasugrel in TAT is contraindicated, however, based mainly on the results of the RE-DUAL-AF where $12 \%$ of patients were treated with ticagrelor $(n=327)$, the 2019 ESC guidelines on chronic coronary syndromes recommended DAT with ticagrelor or prasugrel in pa- tients with a moderate-to-high risk of ST (Class IIb, level of evidence C, Table 2) (2). The North American consensus statement on antithrombotic therapy in patients with $\mathrm{AF}$ undergoing $\mathrm{PCl}$ makes DAT with ticagrelor but not prasugrel as an option for patients with high ischemic and low bleeding risk (24). Other strategies to decrease bleeding risk during DAT and TAT include adding a proton pump inhibitor and avoiding nonsteroidal anti-inflammatory agents; however, these strategies were not tested in RCTs.

\section{Real-life evidence}

Observational studies on antithrombotic therapy following $\mathrm{PCl}$ in anticoagulated AF patients largely reported findings similar to RCTs. Sindet-Pedersen et al. (25), based on the Danish nationwide registry $(n=3222)$, showed for 3 - and 12-month TAT with NOAC, a $1.94 \%$ and $4.50 \%$ decrease in absolute major bleeding risk and similar thromboembolic protection, as compared with TAT with VKA. Of note, DAT with NOAC, when compared with DAT with VKA, resulted in lower absolute risk of $\mathrm{MI}(-1.53 \%$ and $-2.99 \%$ at 3 and 12 months, respectively) with no significant difference in major bleeding, stroke and all-cause mortality. In 2015 a European Heart Rhythm Association Survey showed that most centers preferred VKA over NOACs in TAT after PCI in AF patients with $12 \%$ preferring NOAC. Over $70 \%$ of centers used TAT therapy with aspirin (75-100 mg/ day) and clopidogrel (75 mg/day) for 3 months followed by 3-6 months of DAT in patients with a DES and AF. 
Nearly half of the centers considered bare-metal stents in case of $\mathrm{Ml}$ in the group at high bleeding risk and two-thirds in elective PCI (26).

\section{Antithrombotic therapy in specific subgroups}

There are limited data on the combined antiplatelet and anticoagulant therapy safety, in particular, AF patient subsets, including the elderly, underweight or obesity, patients with cancer, chronic kidney disease, liver injury, thrombocytopenia, and ST $(1,3)$.

\section{Advanced age}

The greater risk of bleeding in older patients with AF makes combined antithrombotic therapy challenging. It appears that in the group above 75 years, similar to the younger subjects, NOAC reduced risk of ICB but increased $\mathrm{GI}$ bleeds compared with VKA (11). In RCTs, apixaban was the only NOAC that showed a reduction of major bleeding among older patients compared with VKA (27). Four large RCTs comparing warfarin and the NOACs in combination with antiplatelets, showed a significant reduction of $35 \%$ in major bleeding for DAT (28). The mean age of study participants was 69.9 and 70.8 years, while the elderly constituted $22.9 \%$ and 34\% (RE-DUAL PCI trial and PIONEER AF-PCI study, respectively) $(7,8)$. In the Spanish study on patients aged $\geq 75$ years with AF undergoing PCI, TAT as compared with DAPT, was associated with a lower rate of thromboembolism (0.6\% vs. 6.9\%) and a higher rate of major bleeding (11.7\% vs. $2.4 \%$, respectively) (28).

\section{Underweight or obesity}

The bleeding risk of antiplatelets, particularly prasugrel, was markedly increased in underweight patients (13). Low body weight may increase NOAC exposure and increase the risk of bleeding (29). Post hoc analyses of RCTs showed similar efficacy and safety of dabigatran in patients with body weight below $50 \mathrm{~kg}$, whereas observational studies suggested higher bleeding risk. Apixaban, for which body weight $\leq 60 \mathrm{~kg}$ (together with age $\geq 80$ years and/or creatinine $\geq 1.5 \mathrm{mg} / \mathrm{dL}$ ) is a dose-reduction criterion, was safer than warfarin in the underweight patients (30). To our knowledge, there have been no outcome data for rivaroxaban use in patients $<60 \mathrm{~kg}$ published to data.

Obesity may enhance platelet reactivity, diminishing effect of antiplatelet drugs, as observed in ex-vivo assays; however, there have been no trials on dosing regimens and long-term outcomes regarding body mass index (BMI). Studies on NOAC reported little or no changes in the volume of distribution and half-life in obese patients, although they did not include patients with extreme obesity. Patients with BMI $\geq 35 \mathrm{~kg} / \mathrm{m}^{2}$ treated with rivaroxaban had a reduced stroke risk compared with the rest of the cohort, and a similar trend was observed for apixaban in a subgroup with $\mathrm{BMI} \geq 30 \mathrm{~kg} / \mathrm{m}^{2}$
(31). Considering limited data on NOAC use in patients with extreme obesity (weight $>120 \mathrm{~kg}$ or BMI $\geq 40 \mathrm{~kg} /$ $\mathrm{m}^{2}$ ), VKA might be considered the first option of treatment. NOAC plasma level measurement and dosage modification under the guidance of a hematologist for patients with extremely low and high body weight may be another option, although this approach has not been tested in long-term clinical studies (32). DAT and TAT should be individualized in this population due to limited data on combined therapy.

\section{Chronic kidney disease}

Chronic kidney disease (CKD) is characterized by an increased risk of thromboembolism and bleeding. The renal elimination varies between NOACs, with the lowest values for edoxaban and apixaban $(27 \%$ and $35 \%$, respectively). Apixaban, edoxaban and rivaroxaban are approved in Europe in patients with CKD and creatinine clearance $(\mathrm{CrCl})$ of $15-29 \mathrm{~mL} / \mathrm{min}$ in a reduced dose and contraindicated if $\mathrm{CrCl}$ is below $15 \mathrm{~mL} / \mathrm{min}$. In the retrospective analysis of RCTs comparing NOACs with VKA in AF patients, the efficacy and safety of NOACs were consistent across subgroups with mild to moderate CKD and without CKD (33). The bleeding benefit of NOAC over warfarin was observed for apixaban but not for dabigatran at lower $\mathrm{CrCl}$ values (27).

However, the landmark NOAC trials in AF patients undergoing $\mathrm{PCl}$ excluded patients with severe renal impairment $(\mathrm{CrCl}$ of $<30 \mathrm{~mL} / \mathrm{min})$ and did not focus on other subgroups with CKD. In the PIONEER AF-PCI trial $27.9 \%$ of patients had $\mathrm{CrCl}$ of 30 to $60 \mathrm{ml} / \mathrm{min}$ and $0.8 \%$ had $\mathrm{CrCl}<30 \mathrm{~mL} / \mathrm{min}(7)$. The AUGUSTUS trial included $8.4 \%$ patients with creatinine $>1.5 \mathrm{mg} / \mathrm{dL}$ (9). Both studies showed the superiority of DAT in the reduction of bleeding complications and the same efficacy in thromboembolism prevention; however, the impact of kidney function on results was not analyzed. As the antiplatelet efficacy of aspirin is lower than clopidogrel, and its use in DAT and TAT increases major bleeding risk, clopidogrel should be administered as the single agent in combined antithrombotic therapy in patients with advanced CKD (34). DAT should be considered as an alternative in patients with mild-to-moderate CKD.

\section{Cancer}

It is estimated that $5 \%$ of patients have or develop AF within the first months after diagnosis of cancer (35). Thromboembolic risk is increased in various types of cancer, with the greatest elevation in the pancreas, ovary, brain and lung cancers, and hematological neoplasms. Specific factors such as thrombocytopenia, neoplastic infiltration of arterial vessels, metastases, radiation therapy increase bleeding risk in cancer (36). AF patients with cancer belong to the group with very high bleeding risk, where TAT after $\mathrm{PCl}$ is rarely instituted, except subjects long-term after a few years of treatment, with good prognosis and without thrombocy- 
topenia (37). Most centers, especially in the first weeks of cancer diagnosis, prefer DAT, i.e. clopidogrel with low-molecular-weight heparin or VKA. The duration of DAT is up to 12 months depending on the oncological status, thromboembolic and bleeding complications during therapy, and may be shortened to 1-6 months in the case of unacceptable bleeding (36). The 2019 ISTH guidelines on anticoagulation in patients with AF and cancer receiving chemotherapy recommend individualized anticoagulation, based on thrombotic/bleeding risk and patient preferences. The preference of NOACs over VKAs or heparins is suggested in patients with newly diagnosed AF, except for subjects with active duodenal ulcer, gastritis, esophagitis, colitis or with luminal GI cancer and an intact tumor (38).

\section{Thrombocytopenia}

Up to $3 \%$ of AF patients have thrombocytopenia defined as a platelet count below 100,000/ $\mu \mathrm{L}$ (39). The PIONEER AF-PCI, RE-DUAL PCI and AUGUSTUS trial excluded patients with a platelet count below 90,000-

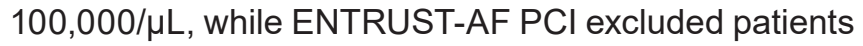
with severe thrombocytopenia $(<50,000 / \mu \mathrm{L})(6-9)$. The current ESC guidelines do not provide any recommendations for the use of DAT and TAT in thrombocytopenic patients $(2,3)$. In recent studies, VKA in patients with moderate thrombocytopenia increased 3-fold the risk of minor bleedings (40). NOAC at reduced dose had acceptable safety and effectiveness in patients with a mean platelet count of $78,000 / \mu \mathrm{L}$ (41). McCarthy et al. based on two RCTs with second-generation drug-eluting stents, where a subgroup of patients with moderate thrombocytopenia was enrolled, recommended shortening DAPT to one month after ACS, avoiding ticagrelor and prasugrel and avoiding TAT in subjects with indication to OAC (39). In patients with AF and platelet count $<50,000 / \mu \mathrm{L}$, the anticoagulation should be individualized given no evidence from randomized trials. Clopidogrel should be preferred in patients with severe thrombocytopenia.

The dual-therapy approach in AF patients undergoing $\mathrm{PCl}$ is now supported by current American and European guidelines. Summary of the current recommendations has been shown in Table 2 and 3.

\section{Conclusions}

Overall, dual antithrombotic therapy with NOAC and $\mathrm{P}_{2 Y_{12}}$ inhibitor (predominantly clopidogrel) is superior to triple therapy (VKA/NOAC + DAPT) in most patients with AF, as shown in RCTs. The excessive bleeding risk prevails benefit in reducing stent thrombosis. Current data suggest that a short course of TAT (e.g., 1 week) should be a default therapy for the majority of patients, followed by DAT for up to 12 months, and then with OAC only. Selected patients at high ischemic risk may be-
TABLE 3. 2018 North American consensus statement on the management of antithrombotic therapy in patients with $\mathrm{AF}$ undergoing $\mathrm{PCl}$ (24).

A double-therapy regimen (OAC plus $\mathrm{P}_{2} \mathrm{Y}_{12}$ inhibitor) should be considered for most patients immediately after hospital discharge.

A triple therapy (extending the use of aspirin) should be considered only for patients at high ischemic/ thrombotic and low bleeding risks. TAT duration should be limited to a short period of time (e.g., 1 month).

NOAC should be preferred over VKA.

Clopidogrel remains the $\mathrm{P}_{2} \mathrm{Y}_{12}$ inhibitor of choice, whereas ticagrelor is a treatment option in patients at high ischemic/ thrombotic and low bleeding risks; prasugrel use in DAT and TAT is contraindicated.

For abbreviations see Table 1 and 2

nefit from a longer course of TAT. The duration of DAT and TAT can be modified based on a clinical setting (elective PCI vs ACS) and individual patient's ischemic and bleeding risks. Individualized therapy in ACS and $\mathrm{PCl}$ patients who required anticoagulation should be considered in the presence of extreme ischemic or bleeding risks.

\section{Acknowledgments}

The study was supported by a grant of Jagiellonian University Medical College (N/41/DBS/000184, to A.U.).

\section{Declaration of conflicting interests}

$\mathrm{AU}$ received lecture honoraria from Bayer, Boehringer Ingelheim, and Pfizer. Other authors declare no conflict of interest.

\section{Contribution statement}

AU, LD - the concept and design of the study, analysis and interpretation of data, revising the article for important intellectual content, final manuscript approval.

\section{References}

1. Crowther MA, Eikelboom JW. Dual and triple antithrombotic therapies: Current patterns of practice and controversies. Kardiol Pol 2018; 76: 937-44. doi: 10.5603/KP.a2018.0112

2. Knuuti J, Wijns W, Achenbach S, et al. 2019 ESC guidelines for the diagnosis and management of chronic coronary syndromes. Eur Heart J 2020; 41: 407-77. doi: 10.1093/eurheartj/ehz425

3. Kirchhof $P$, Benussi S, Kotecha D, et al. 2016 ESC Guidelines for the management of atrial fibrillation developed in collaboration with EACTS. Eur Heart J 2016; 7: 2893-962. doi: 10.1093/eurheartj/ ehw210

4. Dewilde WJM, Oirbans T, Verheugt FWA, et al. Use of clopidogrel with or without aspirin in patients taking oral anticoagulant therapy and undergoing percutaneous coronary intervention: An open-label, randomised, controlled trial. Lancet 2013; 381: 1107-15. doi:10.1016/ S0140-6736(12)62177-1

5. Eikelboom JW, Mehta SR, Anand SS, et al. Adverse impact of bleeding on prognosis in patients with acute coronary syndromes. Circulation 2006; 114: 774-82. doi:10.1161/CIRCULATIONAHA.106.612812

6. Vranckx P, Valgimigli M, Eckardt L, et al. Edoxaban-based versus 
vitamin $\mathrm{K}$ antagonist-based antithrombotic regimen after successful coronary stenting in patients with atrial fibrillation (ENTRUST-AF PCI): a randomised, open-label, phase 3b trial. Lancet 2019; 394: 1335-43. doi: 10.1016/S0140-6736(19)31872-0

7. Gibson CM, Mehran R, Bode C, et al. Prevention of bleeding in patients with atrial fibrillation undergoing PCI. N Engl J Med 2016; 375: 2423-34. doi:10.1056/NEJMoa1611594

8. Cannon CP, Bhatt DL, Oldgren J, et al. Dual Antithrombotic Therapy with Dabigatran after PCI in Atrial Fibrillation. N Engl J Med 2017; 377: 1513-24. doi:10.1056/NEJMoa1708454

9. Lopes RD, Heizer G, Aronson R, et al. Antithrombotic therapy after acute coronary syndrome or $\mathrm{PCl}$ in atrial fibrillation. $\mathrm{N}$ Engl $\mathrm{J}$ Med 2019; 380: 1509-24. doi:10.1056/NEJMoa1817083

10. Potpara TS, Mujovic N, Lip GYH. Meeting the unmet needs to improve management and outcomes of patients with atrial fibrillation: Fitting global solutions to local settings. Polish Arch Intern Med. 2019; 129: 574-6. doi:10.20452/pamw.14996

11. Ruff CT, Giugliano RP, Braunwald E, et al. Comparison of the efficacy and safety of new oral anticoagulants with warfarin in patients with atrial fibrillation: A meta-analysis of randomised trials. Lancet. 2014; 383: 955-62. doi:10.1016/S0140-6736(13)62343-0

12. Liew A, O'Donnell $M$, Douketis J Comparing mortality in patients with atrial fibrillation who are receiving a direct-acting oral anticoagulant or warfarin: A meta-analysis of randomized trials. J Thromb Haemost. 2014; 12: 1419-24. doi:10.1111/jth.12651

13. Roffi M, Patrono C, Collet JP, et al. 2015 ESC Guidelines for the management of acute coronary syndromes in patients presenting without persistent ST-segment elevation: Task force for the management of acute coronary syndromes in patients presenting without persistent ST-segment elevation of. Eur Heart J 2016; 37: 267-315. doi:10.1093/eurheartj/ehv320

14. Ibanez B, James S, Agewall S, et al. 2017 ESC Guidelines for the management of acute myocardial infarction in patients presenting with ST-segment elevation. Eur Heart J 2018; 39: 119-77. doi:10.1093/eurheartj/ehx393

15. Valgimigli M, Bueno H, Byrne RA, et al. 2017 ESC focused update on dual antiplatelet therapy in coronary artery disease developed in collaboration with EACTS. Eur J Cardio-thoracic Surg 2018; 53: 34-78. doi:10.1093/ejcts/ezx334

16. Bansilal S, Bonaca MP, Cornel JH, et al. Ticagrelor for Secondary Prevention of Atherothrombotic Events in Patients With Multivessel Coronary Disease. J Am Coll Cardiol 2018; 71: 489-96. doi:10.1016/j.jacc.2017.11.050

17. Fiedler KA, Maeng M, Mehilli J, et al. Duration of triple therapy in patients requiring oral anticoagulation after drug-eluting stent implantation: The ISAR-TRIPLE trial. J Am Coll Cardiol 2015; 65: 1619-29. doi:10.1016/j.jacc.2015.02.050

18. Grajek S, Olasińska-Wiśniewska A, Michalak M, et al. Triple versus double antithrombotic therapy in patients with atrial fibrillation and stent implantation: A meta-analysis of randomized trials. Kardiol Pol 2019; 77: 837-45. doi:10.33963/KP.14899

19. Lopes RD, Hong H, Harskamp RE, et al. Safety and Efficacy of Antithrombotic Strategies in Patients With Atrial Fibrillation Undergoing Percutaneous Coronary Intervention: A Network Meta-analysis of Randomized Controlled Trials. JAMA Cardiol 2019; 4: 747-55. doi:10.1001/jamacardio.2019.1880

20. Lopes RD, Hong H, Harskamp RE, et al. Optimal Antithrombotic Regimens for Patients With Atrial Fibrillation U ndergoing Percutaneous Coronary Intervention: An Updated Network Meta-analysis. JAMA Cardiol 2020; 5: 582-9. doi:10.1001/jamacardio.2019.6175

21. Gargiulo G, Goette A, Tijssen J, et al. Safety and efficacy outcomes of double vs. triple antithrombotic therapy in patients with atrial fibrillation following percutaneous coronary intervention: A systematic review and meta-analysis of non-Vitamin $\mathrm{K}$ antagonist oral anticoagulant-based randomized clinical trials. Eur Heart J 2019; 40: 3757-67. doi:10.1093/eurheartj/ehz732

22. Potpara TS, Mujovic N, Proietti M, et al. Revisiting the Effects of Omitting Aspirin in Combined Antithrombotic Therapies for Atrial Fibrillation and Acute Coronary Syndromes or Percutaneous Coronary Interventions: Meta-Analysis of Pooled Data From the PIONEER AF-PCI, RE-DUAL PCI, and AUGUSTUS Trial. Europace 2020; 22: 33-46. doi:10.1093/europace/euz259
23. Piccini JP, Jones WS. Triple therapy for atrial fibrillation after PCI. N Engl J Med 2017; 377: 1580-2. doi:10.1056/NEJMe1710753 24. Angiolillo DJ, Goodman SG, Bhatt DL, et al. Antithrombotic therapy in patients with atrial fibrillation treated with oral anticoagulation undergoing percutaneous coronary intervention: A North American perspective-2018 update. Circulation 2018; 138: 527-36. doi:10.1161/CIRCULATIONAHA.118.034722

25. Sindet-Pedersen C, Lamberts $M$, Staerk L, et al. Combining Oral Anticoagulants With Platelet Inhibitors in Patients With Atrial Fibrillation and Coronary Disease. J Am Coll Cardiol 2018; 72(15): 1790800. doi:10.1016/j.jacc.2018.07.054

26. Larsen TB, Potpara T, Dagres $N$, et al. Preference for oral anticoagulation therapy for patients with atrial fibrillation in Europe in different clinical situations: Results of the European Heart Rhythm Association Survey. Europace 2015; 17: 819-24. doi:10.1093/europace/euv116

27. Halvorsen $\mathrm{S}$, Atar D, Yang $\mathrm{H}$, et al. Efficacy and safety of apixaban compared with warfarin according to age for stroke prevention in atrial fibrillation: Observations from the ARISTOTLE trial. Eur Heart J 2014; 35: 1864-72. doi:10.1093/eurheartj/ehu046

28. Sambola A, Mutuberría M, del Blanco BG, et al. Impact of triple therapy in elderly patients with atrial fibrillation undergoing percutaneous coronary intervention. PLoS One 2016; 11: 1-12. doi:10.1371/ journal.pone.0147245

29. Steffel J, Verhamme P, Potpara TS, et al. The 2018 European Heart Rhythm Association Practical Guide on the use of non-Vitamin $\mathrm{K}$ antagonist oral anticoagulants in patients with atrial fibrillation. Eur Heart J 2018; 39: 1330-93. doi:10.1093/eurheartj/ehy136

30. Undas A, Drabik L, Potpara T. Bleeding in anticoagulated patients with atrial fibrillation: practical considerations. Polish Arch Intern Med 2020; 10.20452/pamw.15136. doi:10.20452/pamw.15136

31. Beavers CJ, Heron P, Smyth SS, et al. Obesity and AntiplateletsDoes One Size Fit All? Thromb Res 2015; 136: 712-6. doi:10.1016/j. thromres.2015.07.015

32. Tripodi A, Braham S, Scimeca B, et al. How and when to measure anticoagulant effects of direct oral anticoagulants? Practical issues. Polish Arch Intern Med 2018; 128: 379-85. doi:10.20452/ pamw.4287

33. Reinecke $H$, Engelbertz C, Schäbitz WR. Preventing stroke in patients with chronic kidney disease and atrial fibrillation: Benefit and risks of old and new oral anticoagulants. Stroke 2013; 44: 293541. doi:10.1161/STROKEAHA.113.001701

34. Covic A, Genovesi S, Rossignol P, et al. Practical issues in clinical scenarios involving CKD patients requiring antithrombotic therapy in light of the 2017 ESC guideline recommendations. BMC Med 2018; 16: 1-11. doi:10.1186/s12916-018-1145-0

35. Sanz AP, Gómez JLZ. AF in cancer patients: A different need for anticoagulation? Eur Cardiol Rev 2019; 14: 65-7. doi:10.15420/ ecr.2018.32.2

36. Undas A, Drabik L. Non-vitamin K antagonist oral anticoagulants (NOACs) in cancer patients with atrial fibrillation. Anatol J Cardiol 2019; AJC90766. doi:10.14744/AnatolJCardiol.2019.30766

37. Çetinkal G, Koçaş C, Koçaş BB, et al. Comparative performance of anTicoagulation and risk factors in atrial fibrillation and global registry of acute coronary events risk scores in predicting long-term adverse events in patients with acute myocardial infarction. Anatol J Cardiol 2018; 20: 77-84. doi:10.14744/AnatolJCardiol.2018.54815 38. Delluc A, Wang TF, Yap ES, et al. Anticoagulation of cancer patients with non-valvular atrial fibrillation receiving chemotherapy: Guidance from the SSC of the ISTH. J Thromb Haemost. 2019; 17: 1247-52. doi:10.1111/jth.14478

39. McCarthy CP, Steg GP, Bhatt DL. The management of antiplatelet therapy in acute coronary syndrome patients with thrombocytopenia: A clinical conundrum. Eur Heart J 2017; 38: 3488-92. doi:10.1093/eurheartj/ehx531

40. Lai YF, Goh DYT, How SY, et al. Safety and efficacy of warfarin in patients with moderate thrombocytopenia. Thromb Res 2017; 155: 53-7. doi:10.1016/j.thromres.2017.05.007

41. Janion-Sadowska A, Papuga-Szela E, Lukaszuk R, et al. NonVitamin $\mathrm{K}$ antagonist oral anticoagulants in patients with atrial fibrillation and thrombocytopenia. J Cardiovasc Pharmacol 2018; 72: 153-60. doi:10.1097/FJC.0000000000000607 